\title{
Quantum Chemical Studies on the Inhibiting Effect of Bipyrazoles on Steel Corrosion in $\mathrm{HCl}$
}

\author{
K. LAAREJ, M. BOUACHRINE\#, S. RADI, S. KERTIT ${ }^{\S}$ and B. HAMMOUTI* \\ Faculté des Sciences, B. P. 717, 60000 Oujda - Morocco. \\ "Faculté Polydisciplinaire, Taza, Morocco. \\ ${ }^{\S}$ Les Ecoles AL ROCHD, Sala Aljadida, Morocco. \\ hammoutib@yahoo.fr
}

Received 12 August 2009; Accepted 7 Octobre 2009

\begin{abstract}
Correlation of the efficacy of some bipyrazoles, $N, N$-bis(3,5-dimethylpyrazol-1-ylmethyl)-cyclohexylamine (Bip 1), N,N-bis(3,5-dimethylpyrazol-1ylmethyl)-ethanolamine (Bip 2), N,N-bis(3,5-dimethylpyrazol-1-ylmethyl) allylamine (Bip 3) and $N, N$-bis(3-carboethoxy-5-methylpyrazol-1-ylmethyl)cyclohexylamine (Bip 4), against the corrosion of mild steel in $\mathrm{HCl}$ is discussed using density functional approach B3LYP/6-31G(d) calculations. The bipyrazole inhibitors exhibited the highest inhibition efficiency. The quantum chemical parameters calculated are, the highest occupied molecular orbital (HOMO), the lowest unoccupied molecular orbital (LUMO), the gap energy $(\Delta \mathrm{E})$, the dipole moment $(\mu)$, the softness $(\sigma)$ and the total energy (TE).
\end{abstract}

Keywords: bipyrazoles, Inhibition, Corrosion, DFT calculations.

\section{Introduction}

The protection of metals against corrosion may be achieved by adding inhibitors in small concentrations to its environment. Numerous studies were performed on the pyrazolic molecules which exhibited good inhibiting effect on corrosion of metallic materials ${ }^{1-8}$. The reactivity of inhibitors is mainly interpreted by adsorption on the metal surface and depends on the molecular structure of inhibitors such as the heteroatoms, the functional group and electronic density at the donor or acceptor atom and $\pi$ orbital character ${ }^{9-13}$. In other words, the electronic structure of the organic compounds has a key influence on their corrosion inhibition efficiency. The molecular structure, including the electronic parameters, can be obtained by means of the theoretical calculations by using the computational methodologies of quantum-chemistry. Quantum chemical calculation has been used recently to explain the mechanism of corrosion inhibition ${ }^{14-19}$ and proved to be a very powerful tool for studying the mechanism ${ }^{20-22}$. The survey of theoretical corrosion literature presented by $\mathrm{Gece}^{22}$ demonstrates that quantum chemistry is a powerful tool to study the fundamental, molecular-level 
processes related to corrosion inhibition. However, much care must be taken in planning these studies, as calculations performed with inaccurate methods or with an insufficient dataset can easily lead to erroneous conclusions. The role of quantum chemistry in corrosion inhibitor studies is likely to increase in the future, as the focus of investigations shifts toward complicated chemical mechanisms. However, the restrictions caused by the high computational effort of the calculations mean that quantum chemical methods will not in the foreseeable future be able to replace experimental corrosion studies or computationally less expensive methods for the processes related to corrosion inhibition.
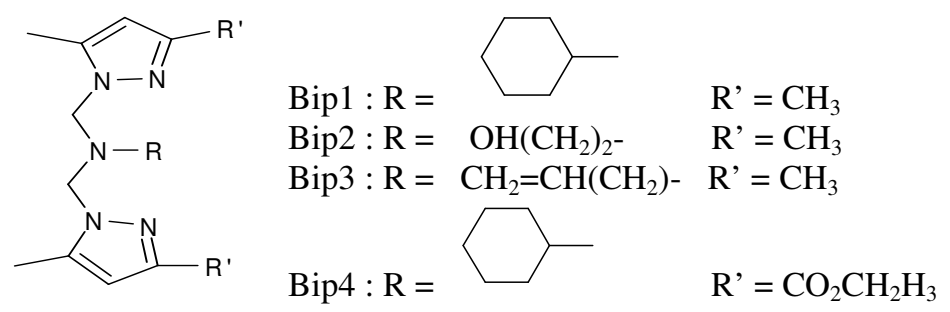

Figure 1. Molecular structures of the investigated bipyrazoles.

The objective of this paper is to correlate the effect of structural parameters of bipyrazole derivatives through their quantum parameters to explain their inhibition efficiencies. Computational calculation were obtained by means of B3LYP/STO-3G(d) method. Parameters (total energy, $\triangle \mathrm{E}$, the HOMO and LUMO energies, dipole moment $(\mu)$ and global hardness $(\eta)$ ) were calculated. The bipyrazoles were investigated theoretically using B3LYP density function approach (Figure. 1).

\section{Experimental}

DFT method of three parameter compound functional of Becke (B3LYP) ${ }^{23}$ was used to study these compound. The $6-31 \mathrm{G}^{*}$ basis set was used for all calculations ${ }^{24}$. To obtain the final stable conformation, calculations of these geometries were performed without constraint on the dihedral angles. The calculations were carried out using the GAUSSIAN 03 program $^{25}$. The theoretical band gaps calculated for isolated chains are expected to be about $0.2 \mathrm{eV}$ larger than condensed phase values ${ }^{26}$. When taking into consideration this difference, we have demonstrated that the B3LYP/6-31G(d) method has the particularity to reproduce gap values similar to those of the experience ${ }^{27}$.

\section{Results and Discussion}

The inhibition efficiency of bipirazole derivatives as corrosion inhibitors of mild steel were investigated experimentally ${ }^{28}$ (Table 1). It is found that the inhibitors Bip 1, Bip 2 and Bip 3 have approximately equal inhibiting effectiveness than the effectiveness of Bip 4 is lower.

Quantum chemical indices are obtained from the calculations such as $\mathrm{E}_{\mathrm{HOMO}}, \mathrm{E}_{\mathrm{LUMO}}$, $\Delta \mathrm{E}=\mathrm{E}_{\mathrm{LUMO}}-\mathrm{E}_{\mathrm{HOMO}}$, the dipole moment, $(\mu)$, the total energy $(\mathrm{TE})$ and the softness $(\sigma)$ are summarized in Table 1. The optimized molecular structures with minimum energies obtained from the calculations are given in Figure 2.

The HOMO is the orbital that could act as an electron donor, since it is the outermost (highest energy) orbital containing electrons. The LUMO is the orbital that could act as the electron acceptor, since it is the innermost (lowest energy) orbital that has room to accept electrons. According to the frontier molecular orbital theory, the formation of a transition state is due to an interaction between the frontier orbitals (HOMO and LUMO) of reactants ${ }^{16}$. 
The energy of the HOMO is directly related to the ionization potential and the energy of the LUMO is directly related to the electron affinity.

Table 1. Calculated quantum chemical parameters of the bipyrazole derivatives.

\begin{tabular}{ccccc}
\hline Parameter & Bip 1 & Bip 2 & Bip 3 & Bip 4 \\
\hline $\mathrm{E}_{\text {HOMO, }} \mathrm{eV}$ & -5.781 & -6.103 & -6.072 & -6.351 \\
$\mathrm{E}_{\mathrm{LUMO}} \mathrm{eV}$ & 0.225 & 0.516 & 0.407 & -0.749 \\
$\Delta \mathrm{E}, \mathrm{eV}$ & 6.303 & 6.619 & 6.479 & 5.602 \\
$\mathrm{E} \%, \mathrm{w} / \mathrm{elec}$. & $92 / 93$ & $90 / 91$ & $94 / 94$ & $87 / 88$ \\
$\mu$ (debye) & 2.959 & 2.326 & 3.155 & 3.517 \\
$\chi, \mathrm{eV}$ & 2.778 & 2.793 & 2.832 & 3.550 \\
$\eta, \mathrm{eV}$ & 3.003 & 3.309 & 3.239 & 2.801 \\
$\sigma$ & 0.333 & 0.302 & 0.308 & 0.357 \\
$\mathrm{TE}, \mathrm{kcal} / \mathrm{mol}$ & -971.77 & -896.28 & -859.15 & -1432.88 \\
\hline
\end{tabular}

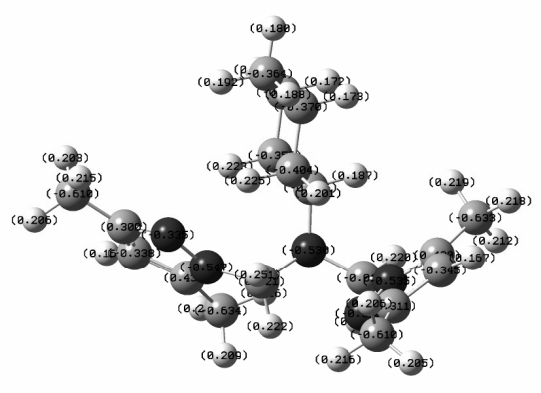

Bip 1

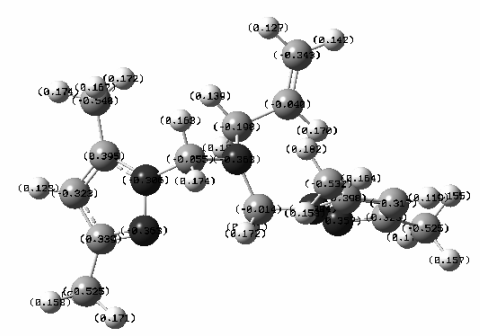

Bip 3

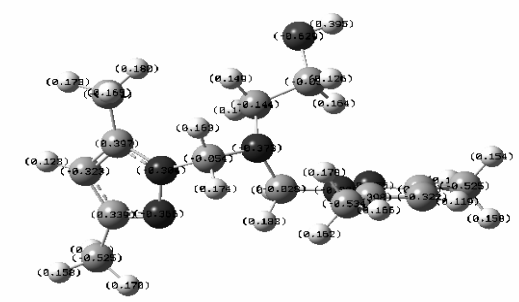

Bip 2

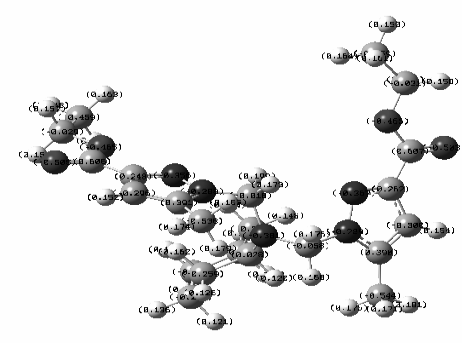

Bip 4

Figure 2. The optimized molecular structure of the inhibitor molecules

Highest occupied molecular orbital energy $\left(E_{\text {Номо }}\right)$ and lowest unoccupied molecular orbital energy $\left(E_{\mathrm{LUMO}}\right)$, also called the frontier orbitals, determine the possibility of the molecule to interact with other reactants. $\mathrm{E}_{\text {Номо }}$ is often a measure of electron donating ability of the molecule. High value of $\mathrm{E}_{\mathrm{HOMO}}$ is likely to indicate a tendency of the molecule to donate electrons to appropriate acceptor molecule of low empty molecular orbital energy. The energy of the lowest unoccupied molecular orbital, $\mathrm{E}_{\mathrm{LUMO}}$, denotes the ability of the molecule to receive electrons. In other words, lower values of $\mathrm{E}_{\mathrm{LUMO}}$, are more probable to accept electrons. So, the gap energy, i.e. the difference in energy between the HOMO and LUMO, is an important stability index. 
In our study, values of HOMO energy may be good tool to interpret the efficiency of bipyrazoles obtained. The calculations show that the Bip 1, Bip 2 and Bip 3 are the highest HOMO level at $-5.781,-6.103$ and $-6.072 \mathrm{eV}$ respectively (Figure 3). It is clear that the lower HOMO corresponds to Bip $4(-6.351 \mathrm{eV})$ which exhibited the lower inhibition efficiency and the highest value is obtained by Bip 1-3, the best ones. The lowest LUMO levels obtained are 0.225 , 0.516 and $0.407 \mathrm{eV}$, Figure 4. This can explain that the highest inhibition efficiency of Bip 1, Bip 2, Bip 3 molecule are due to the increasing energy of the HOMO and the decreasing energy of the LUMO. This is in a good agreement with the experimental observations suggesting that the Bip 1, Bip 2, Bip 3 are the highest inhibition efficiency among the investigated inhibitors.

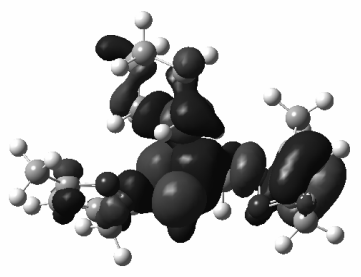

Bip 1

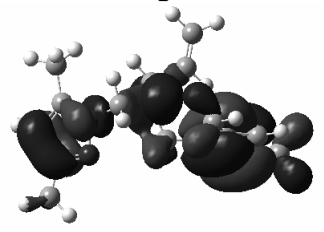

Bip 3

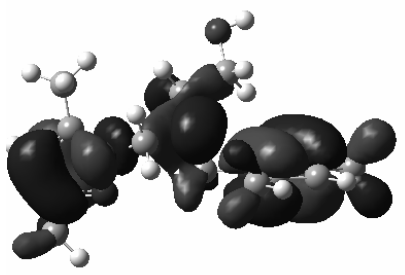

Bip 2

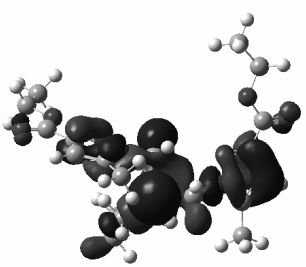

Bip 4

Figure 3. The highest occupied molecular orbital (HOMO) of the inhibitors.

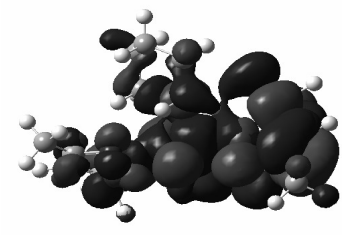

Bip 1

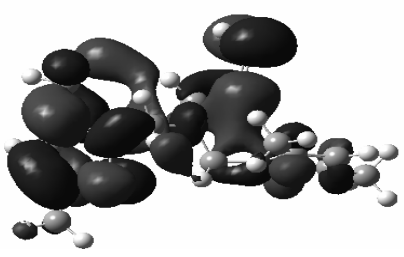

Bip 3

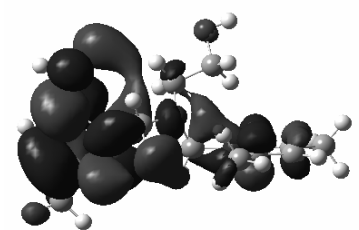

Bip 2

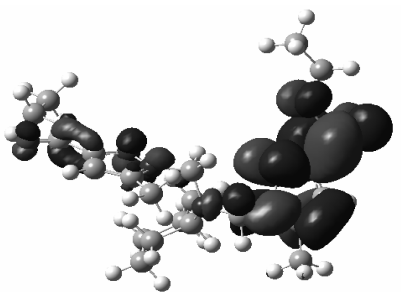

Bip 4

Figure 4. The lowest unoccupied molecular orbital (LUMO) of the inhibitors.

The dipole moment $(\mu)$ is another parameter of the electronic distribution in a molecule and is the measure of polarity of a polar covalent bond ${ }^{22}$. No significant relationship has been found between the dipole moment values and inhibition efficiencies ${ }^{22}$. 
The estimation of the total energy gives good information, the lower TE obtained is related to BIP 4 which exhibited weaker inhibition. The higher TE $\left(-859.15 \mathrm{kcal} \mathrm{mol}^{-1}\right)$ confirms the higher stability of BIP 3 .

The gap energy, $\Delta \mathrm{E}=\left(\mathrm{E}_{\mathrm{LUMO}}-\mathrm{E}_{\mathrm{HOMO}}\right)$, is an important parameter as a function of reactivity of the inhibitor molecule towards the adsorption on metallic surface. As $\Delta \mathrm{E}$ decreases, the reactivity of the molecule increases leading to increase the inhibition efficiency of the molecule; and large gap energy indicates high stability for the molecule in the chemical reaction. Figure 5 summarizes a schematic of diagrams of frontier molecular orbitals for the investigate inhibitors to their estimated energy gap $\Delta \mathrm{E}$. Inhibition of corrosion is generally interpreted by adsorption of inhibitor molecules onto the metal surface. Two modes of adsorption can be envisaged. The physical adsorption requires the interaction of electrically charged metal surface and charged species in the bulk of the solution. Chemisorption mode implies charge sharing or charge transfer from the inhibitor molecule to the vacant orbitals of metal having low energy. The effect of temperature on efficacy of bipyrazoles and adsorption parameters showed that physisorption phenomenon is more favoured. Furthermore, regarding the molecular structure of studied inhibitors, we may support the physical adsorption type. The presence of stable group in Bip 1-3 are responsible of the higher inhibitory effect, but the presence of ester group in Bip 4 is rapidly transformed in acid group in $\mathrm{HCl}$ solutions. This factor is hugely determining in decrease inhibition efficiency of Bip 4 as encountered in previous work ${ }^{29}$.

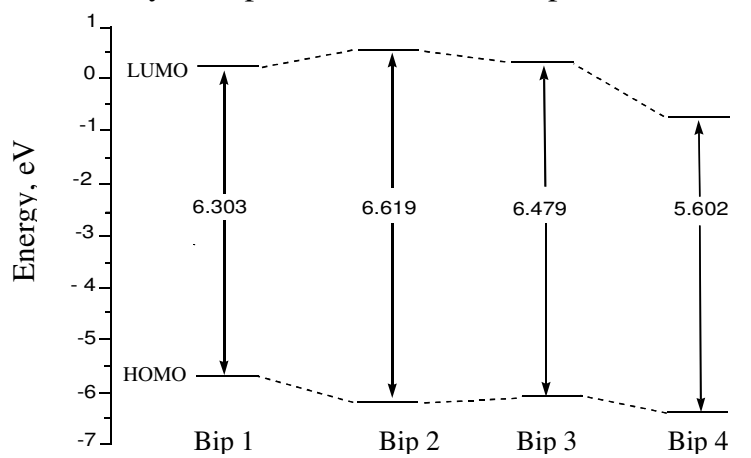

Figure 5. Correlation diagram of frontier molecular orbitals for the investigate inhibitors and their calculated $\Delta \mathrm{E}$.

Other indicators are absolute electronegativity, $\chi$, and absolute hardness, $\chi$ is a chemical property that describes the ability of a molecule to attract electron towards itself in a covalent bond, while the absolute hardness is measured by the energy gap between the lowest unoccupied and highest occupied molecular orbitals. Absolute softness, $\sigma$ is defined as the reciprocal of the hardness. $\chi, \eta$ and $\sigma$ are calculated using the energies of the HOMO and the LUMO orbitals of the inhibitor molecule are related to the ionization potential, I, and the electron affinity, A, respectively, by the following relations:

where $\mathrm{I}=-\mathrm{E}_{\mathrm{HOMO}}$ et $\mathrm{A}=-\mathrm{E}_{\mathrm{LuMO}}$

$$
\chi=\frac{I+A}{2} ; \eta=\frac{I-A}{2} \text { and } \sigma=\frac{2}{I-A}
$$

The results deduced indicate that the electron flow will happen from the molecule with the low electronegativity towards that of a higher value, until the chemical potentials are the same. In our case, the best inhibitory effect is shown by Bip 1-3 with low electronegativity. Bip 4 possesses the higher value. 


\section{Conclusion}

Through DFT (B3LYP/6-31G(d)) method, the following conclusions may be drawn:

- The HOMO, LUMO and gap energies may be used to correlate to the inhibition efficiency,

- The dipole moment has no explanation towards inhibition efficiency,

- The total energy determined is good tool to explain inhibition efficiency of studied inhibitors,

- The best inhibitory effect of BIP 1-3 may be due to low electronegativity.

\section{References}

1. Herrag L, Chetouani A, Elkadiri S, Hammouti B and Aouniti A, Port Electrochim Acta, 2008, 26, 211.

2. Benabdellah M, Touzani R, Aouniti A, Dafali A, El Kadiri S, Hammouti B and Benkaddour M, Mater Chem Phys., 2007, 105, 373.

3. Tebbji K, Bouabdellah I, Aouniti A, Hammouti B, Oudda H, Benkaddour M and Ramdani A, Mater Lett., 2007, 61, 799.

4. Tebbji K, Hammouti B, Oudda H, Ramdani A and Benkadour M, Appl Surf Sci., 2005, 252, 1378.

5. Chetouani A, Hammouti B, Benhadda T and Daoudi M, Appl Surf Sci., 2005, 249, 375.

6. Elayyachy M, Elkodadi M, Aouniti A, Ramdani A, Hammouti B, Malek F and Elidrissi A, Mat Chem Phys., 2005, 93, 281.

7. Bouklah M, Hammouti B, Benkaddour M, Attayibat A and Radi S, Pigment and Resin Technology, 2005, 34, 197.

8. Touhami F, Aouniti A, Abed Y, Hammouti B, Kertit S, Ramdani A and Elkecemi K, Corros Sci., 2000, 42, 929.

9. Saratha R and Vasudha VG, E-Journal Chemistry, 2009, 6, 1003.

10. Rafiquee M Z A, Khan S, Saxena N, and Quraishi M A, J Appl Electrochem., 2009, 39, 1409.

11. Khaled K F, Fadl-Allah S A and Hammouti B, Mater Chem Phys., 2009, 117, 148.

12. Upadhyay R K and Mathur S P, E Journal Chemistry, 2007, 4, 408.

13. Faska Z, Bellioua A, Bouklah M, Majidi L, Fihi R, Bouyanzer A and Hammouti B, Monatshefte fur Chemie, 2008, 139, 1417.

14. Khaled K F, Electrochem Acta, 2009, 54, 4345.

15. Arslan T, Kandemirli F, Ebenso E E and Love I and Alemu H, Corros Sci., 2009, 51, 35.

16. Issa R M, Awad M K and Atlam F M, Appl Surf Sci., 2008, 255, 2433.

17. Jamalizadeh E, Jafari A H and Hosseini S M A, J Molec Struct (Theochem.), 2008, 870, 23.

18. Zhang D Q, Cai Q R, Gao L X and Lee K Y, Corros Sci., 2008, 50, 3615.

19. Sheikhshoaie I, Baghaei F and Dadgarnezhad A, Asian J Chem., 2006, 1, 1903.

20. Gece G and Bilgiç S, Corros Sci., 2009, 51, 1876.

21. Bouklah M, Hammouti B, Lagrenée M and Bentiss F, Corros Sci., 2006, 48, 2831.

22. Gece G, Corros Sci., 2008, 50, 2981.

23. Becke A D, J Chem Phys., 1993, 98, 5648.

24. Hehre W J, Ditchfiesld R and Pople J A, J Chem Phys., 1972, 56, 2257.

25. Frisch M J, Trucks G W, Schlegel H B, et al., GAUSSIAN 03, Revision B.04, Gaussian, Inc., Pittsburgh PA, 2003.

26. Salzner U, Lagowski J B, Pickup P G and Poirier R A, Synth Met., 1998, 96, 177.

27. Bouzakraoui S, Bouzzine S M, Bouachrine M and Hamidi M, Sol Energ Mater Sol Cell., 2006, 90, 1393.

28. Elouafi A, Hammouti, B, Oudda H, Kertit S, Touzani R and Ramdani A, Anti-Corros Meth Mat., 2002, 49, 199.

29. Chetouani A, Daoudi M, Hammouti B, Benhadda T and Benkaddour M, Corros Sci., 2006, 48, 2987. 


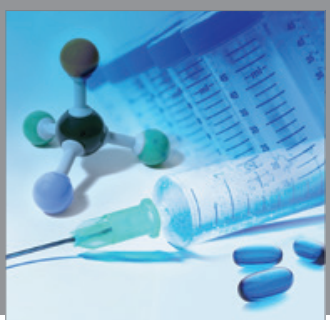

International Journal of

Medicinal Chemistry

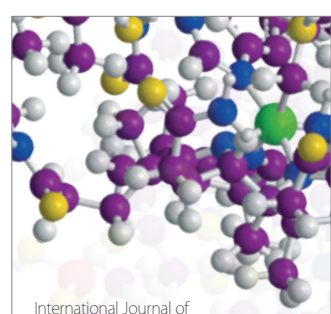

Carbohydrate Chemistry

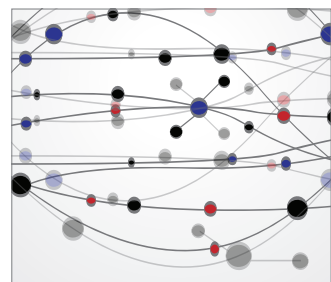

The Scientific World Journal
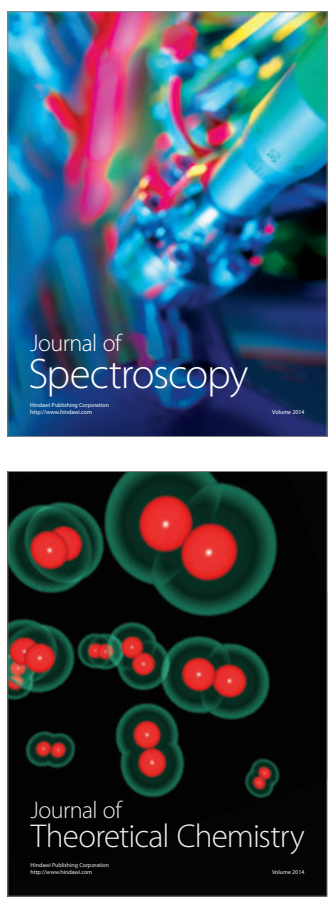
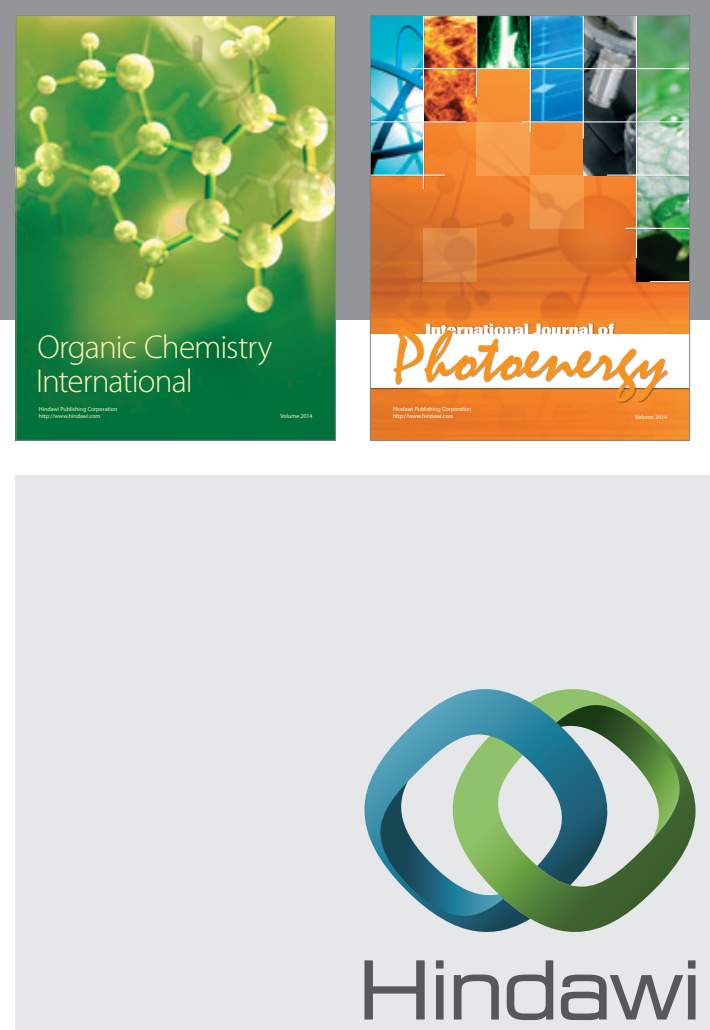

Submit your manuscripts at

http://www.hindawi.com
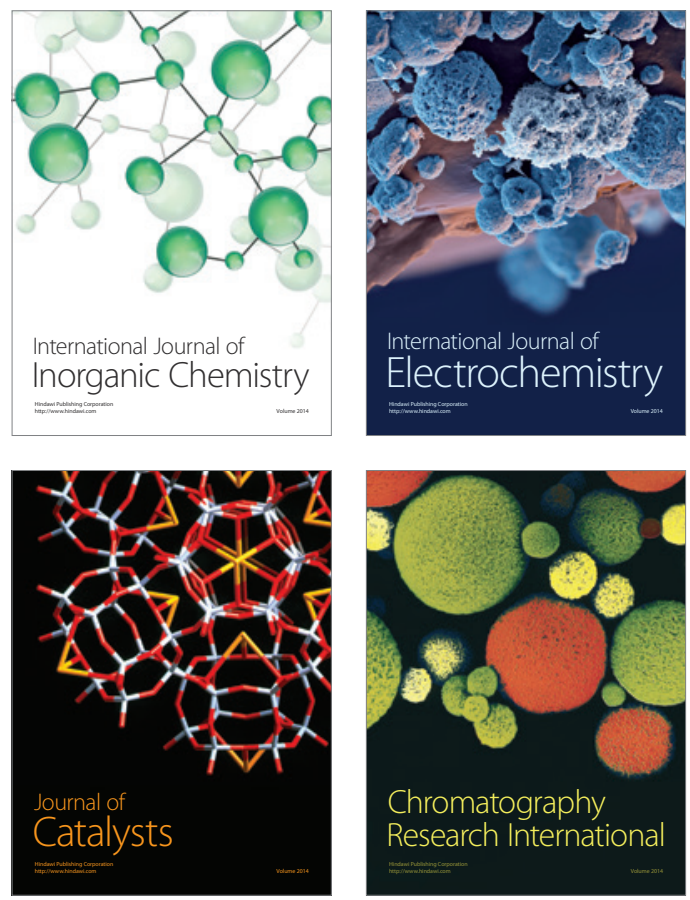
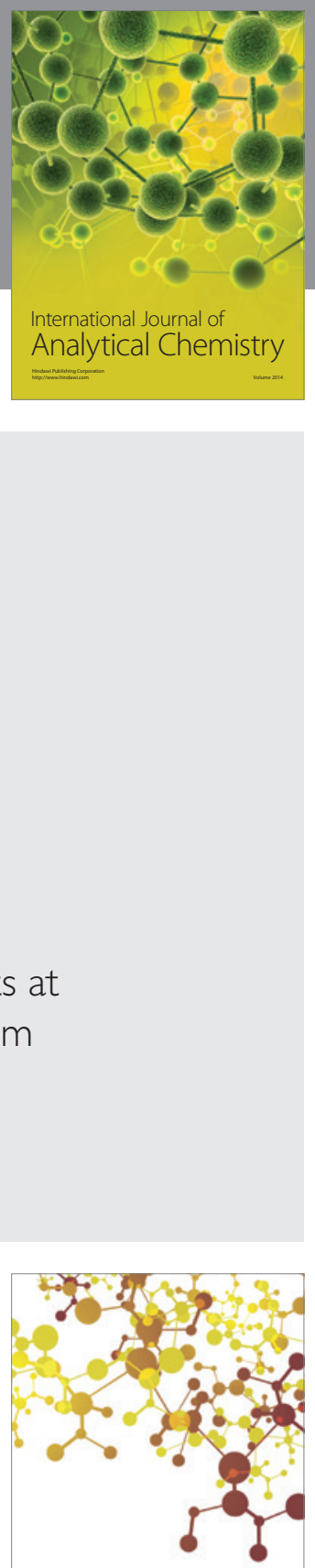

Journal of

Applied Chemistry
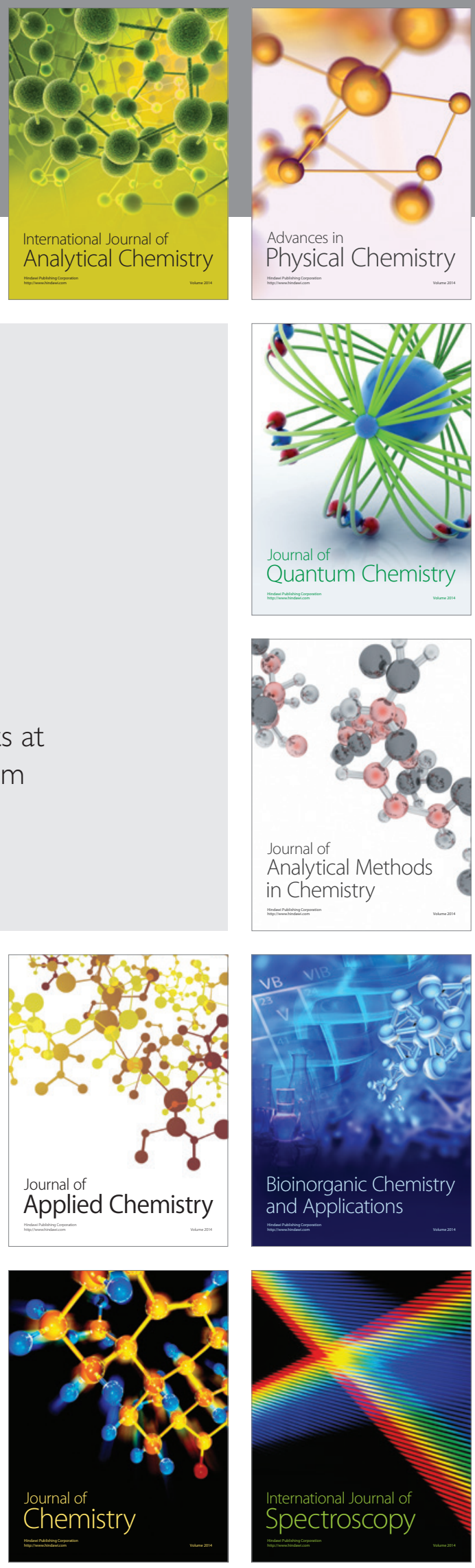